\title{
Approaches to planning your career
}

Lara Isbel

There are a lot of hills in Scotland. Some people climb them for fun. Others get dragged up them by their outdoorsy friends. I've generally been a bit sceptical about the joys of walking up hills for hours just to walk back down again, but I'm slowly being won over.

Time outdoors can provide a useful opportunity for reflection and some of the principles of planning a successful day in the hills can also be applied to managing your career.

\section{Method}

1. Have a plan. How big the plan needs to be depends on your timescales. You might be mapping out a whole PhD, or just trying to figure out how to get something useful done this afternoon. But without a sense of direction, it's just an aimless wander. Aimless wanders are all well and good, provided they are an active choice. Otherwise they are a luxury you may not be able to afford.

2. Be aware of the wider environment. If you go walking in Scotland, your plans are heavily influenced by the weather. Work is only one aspect of your life. If other parts of your life are particularly challenging - caring for young children or elderly parents, or going through a divorce or bereavement, or working with horrendous colleagues or any number of things that leave you reeling, don't hold yourself to the same expectations of progress when life is carefree. Climbing a hill in sunshine and good weather can be straightforward; the same hill in a blizzard can be perilous. Careers are long and life inevitably has storms at certain points. Look after yourself and accept that there will be times for pausing or sustaining your career as well as times for growing and developing it. Your health is more important than your job.

3. One step at a time. It is possible to climb many enormous mountains, just not in a single step. Multitasking is rarely productive. The more you can focus on one thing and then another, the less time you will waste trying to tune back into fragmented tasks. This may be easier to say than do with the volume of work and varied commitments you are trying to balance, but it is more important in these circumstances to find focus. Notice which times of day you have most energy and protect this time (as much as possible) for your most challenging work.

4. Ask for help if you need it. The duties people can cover in a single role can be very wide. If you are trying something new, be realistic about how long it will take to build up your expertise. Start with smaller projects, looking for mentors or experienced colleagues and relevant training courses. Focus on what to improve, figure out your strategy and give yourself time. 


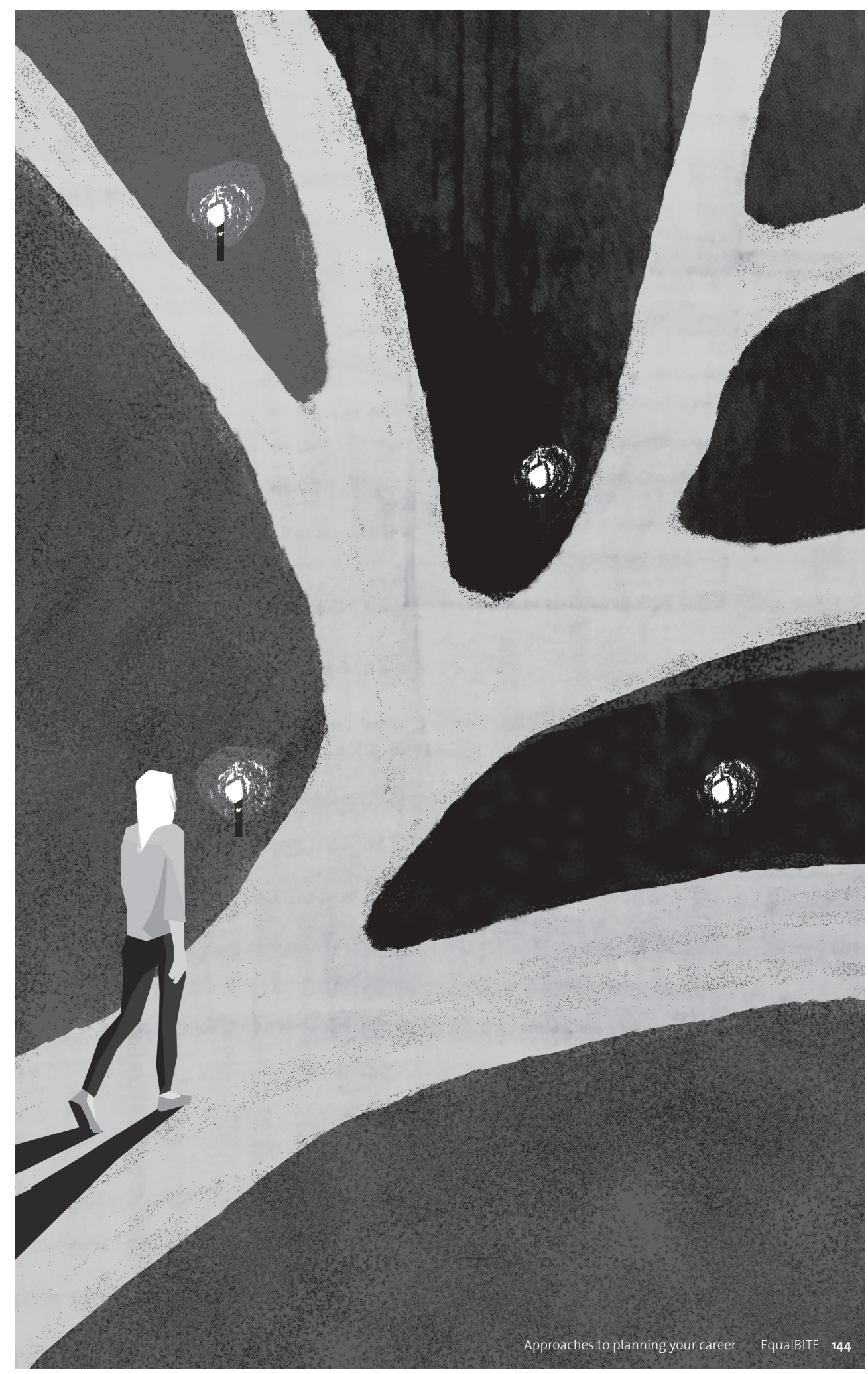

Lara Isbel - 9789463511438 
5. Celebrate small wins. Complex projects can take ages to complete. Take time to identify and celebrate the milestones along the way. This doesn't need to be anything major, just a small thing that will bring you a little bit of joy. This can counterbalance the inevitable setbacks.

6. Change the route. Things don't always go according to plan. If you keep getting stuck with a project, sometimes you need to have a break from it and then approach it from a whole new angle. A detour is still moving. If it's still not working, cut your losses and move on to something else.

7. Save positive feedback. If you get a nice email or other boost to your confidence, keep a note of it. Later, when you are in the depths of despair or feeling stuck, rereading these can help you to rediscover some confidence. On a related note, if you appreciate the contribution someone has made to your project or if they have produced a great bit of work: tell them.

8. Reflect on your progress. An advantage of going uphill as it is easier to look back and see how far you have travelled. Tackle the dread of a never-ending to-do list by keeping a 'have- done' list. Spend 10 minutes at the end of your week scanning through the list of all the things you did manage to get done. This makes the list to tackle next week less daunting.
It is also helpful to schedule time for a broader review every six months of what you have accomplished and to check you are still on the right track.

9. Savour your success. A highlight of climbing mountains is taking a bit of time to enjoy the view at the top, a reward for some strenuous effort. If you have a project on at work that has been incredibly tough to complete - celebrate it. The things that most mattered to you at 16 or 26 might be a distant memory now. If you don't celebrate the real highs of your career, you'll have forgotten what they were by the time you retire or forgotten how momentous they seemed at the time. If you've achieved something you are proud of, acknowledge it, preferably in the company of people you care about. And celebrate their successes too.

10. Reassess the plan. Big successes and big setbacks are useful points to re-evaluate the overall plan. Do you still want to climb the mountains you thought you did? Are your goals things you want to achieve or things you 'ought to' or 'should' achieve? Our career aspirations and priorities shift. The more your work priorities are aligned to your career aspirations, the more job satisfaction you will have and it will be easier to stay motivated. This is your career. Only you can decide what is most important, what brings you the most energy and what inspires you the most. 